\title{
The good news is, we repaired your baby's coarctation...
}

\author{
William M. DeCampli, MD, PhD
}

\footnotetext{
From The Heart Center, Arnold Palmer Hospital for Children; and the Department of Clinical Sciences, College of Medicine, University of Central Florida, Orlando, Fla.

Disclosures: Author has nothing to disclose with regard to commercial support.

Received for publication Sept 29, 2016; revisions received Sept 29, 2016; accepted for publication Sept 30, 2016; available ahead of print Nov 4, 2016.

Address for reprints: William M. DeCampli, MD, PhD, Arnold Palmer Hospital for Children, 80 W Miller St,

Orlando, FL 32813 (E-mail: William.decampli@ucf.edu or William.decampli@orlandohealth.com).

J Thorac Cardiovasc Surg 2017;153:415-7

$0022-5223 / \$ 36.00$

Copyright (C) 2016 by The American Association for Thoracic Surgery

http://dx.doi.org/10.1016/j.jtcvs.2016.09.067
}

The bad news is that, despite the apparent simplicity of repair, coarctation is associated with continued risk of morbidity and decreased life expectancy, mainly stemming from the effects of chronic and often relatively refractory hypertension. This risk is frequently present despite the absence of residual coarctation. In a recent systematic review, the overall prevalence of hypertension among patients with repaired coarctation was $32.5 \%$ (range, $25 \%-68 \%)^{2}$

Our current state of knowledge includes a few key findings, as follows:

1. The prevalence of hypertension increases with age and time from surgical intervention.

2. The prevalence of exercise-induced hypertension is significant $(36 \%)$, and most of these patients go on to have chronic hypertension develop.

3. Early repair (in infancy) may or may not reduce the risk of subsequent development of hypertension. ${ }^{5}$

4. Perioperative hypertension is associated with a higher risk of chronic hypertension. ${ }^{6}$

5. In some studies, patients who undergo repair with primary anastomosis have been found to have lower systolic blood pressure than is seen in those who undergo subclavian flap or patch aortoplasty.

Observations that contribute to our understanding of the pathophysiology of hypertension in repaired coarctation are at least fivefold, as follows:

1. Patients with repaired coarctation have reduced arterial response to nitroglycerin (INN glyceryl trinitrate), impaired flow-mediated dilatation, increased carotid intima-media thickness, increased forearm pulse wave velocity, and decreased spontaneous baroreceptor sensitivity. These characteristics are typical of "stiff" peripheral vasculature associated with systolic hypertension. ${ }^{2}$

2. The ascending aorta is less compliant ("stiffer") in patients with repaired coarctation than in patients with normal anatomy.

3. Patients with repaired coarctation who have a so-called "Gothic arch" (one that is more angulated in its transverse renalase."

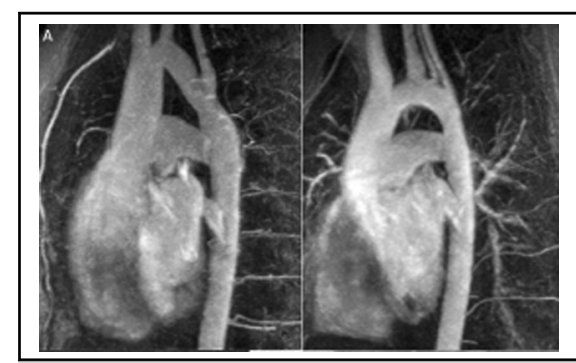

Gothic arch (left) after coarctation repair-a cause of hypertension? From Ou et al.

\section{Central Message}

Hypertension is the most important morbidity after coarctation repair. If aortic arch shape is causally related to this morbidity, there may be something we can do about it.

See Article page 418 .

portion) have a much greater prevalence of hypertension $(45.5 \%)$ than do those with a normally shaped arch $(4.6 \%)$ (Figure 1$){ }^{8}$

4. Some studies have claimed that these patients have a "hyperactive" renin-angiotensin system and low plasma

5. All these findings correlate with at least mild abnormalities in indices of left ventricular mass and function. ${ }^{10,11}$

The article in this issue of the Journal by Bruse and coworkers $^{11}$ further analyzes the apparent relationships of aortic anatomy, hypertension, and ventricular dysfunction in this population. ${ }^{11}$ Bruse and coworkers ${ }^{11}$ correctly recognize that limited morphometric indices (not to mention qualitative descriptions, such as "Gothic arch") are insufficient for complete categorization of the anatomic correlates with risk for hypertension or ventricular dysfunction in the population. They have used statistical shape analysis, a technique used in criminology, medical image analysis, and geographic profiling, to characterize aortic arch shapes in terms of a set of "deformation vectors" applied to a calculated "mean shape," a concept known as diffeomorphology. In the final analysis, they too have found that a Gothic-type arch and such other features as tortuosity, mild isthmus narrowing, and a long, slim ascending aorta are associated with mild ventricular dysfunction. They have also found a trend toward an association between hypertension and Gothic arch and mildly dilated ascending aorta. The article's uniqueness lies in the use of a more quantitative, objective description of aortic arch anatomy. Its significance lies in its corroboration of the results of 
several other studies that have shown the Gothic-type arch to be associated with abnormal cardiovascular physiology after repair of coarctation.

How can we compile these observations to make sense of hypertension after repair of coarctation? The answer depends on "what causes what, and when." It is possible, for example, that coarctation is just an innocent bystander in a case of inborn, pervasive vasculopathy or neuroendocrinopathy. That proposition would still raise the question of why the vasculopathy is associated with, albeit not caused by, the coarctation or its repair. A recent study, in fact, finds no relationship between hypertension (high pulse pressure) and abnormal activation of the renin-angiotensinaldosterone system after repaired coarctation. ${ }^{12}$ Another possibility is that we are underestimating the incidence of subtle residual impedance at the coarctation repair site. One would have expected, however, that studies performed with catheterization or cardiac magnetic resonance imaging would have elucidated this association by now. If such studies haven't yet been done, they should be. A third possibility is that the association of hypertension with coarctation is confounded by the high prevalence of bicuspid aortic valve (BAV). Bicuspid aortic valve, however, is not by itself associated with hypertension. Additionally, many studies demonstrating the association between coarctation and hypertension specifically excluded patients with bicuspid aortic valve.

Ignoring the aforementioned possibilities, we are certain of two facts. First, coarctation is relatively commonly associated with Gothic arch (23\%-36\%) and other deformations elucidated by the article of Bruse and coworkers ${ }^{11}$ (prevalence not yet well known). Second, neither the ventricle nor the peripheral vasculature "sees" the aortic anatomy. They both only "feel" the mechanical effects of blood flow. These facts suggest the possibility that abnormal flow dynamics imposed by the abnormal arch anatomy precipitates the chain of events leading to the clinical picture of hypertension in patients with Gothic arch. Two groups-Donazzan and coworkers ${ }^{13}$ in Padua and $\mathrm{Ou}$ and coworkers ${ }^{1}$ in Paris- used cardiac magnetic resonance imaging measurements to show that patients with Gothic arch, as compared to patients with normal arch anatomy, had increased systolic backward wave amplitude, greater loss of systolic peak amplitude between the ascending and descending aorta, and decreased ascending aortic distensibility. The implication of these finding is that there is a change in impedance in the Gothic arch, undoubtedly near its hairpin turn, that causes a reflection wave early in systole. The result is increased ventricular afterload and a mismatch of ventricular and arterial elastance. The mismatch may be further increased by adverse remodeling of the ascending aortic wall as a result of wall stress, leading to lower aortic compliance. The ventricle responds with hypertrophy and diastolic stiffening in an attempt to normalize

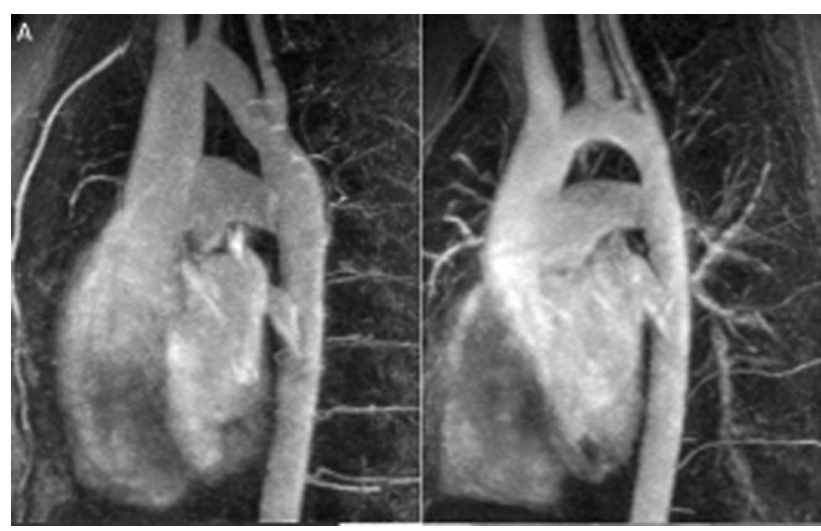

FIGURE 1. Gothic arch (left) after coarctation repair-a cause of hypertension? Reprinted with permission from Ou P, Celermajer D, Raisky O, Jolivet O, Buyens F, Herment A, et al. Angular (Gothic) aortic arch leads to enhanced systolic wave reflection, central aortic stiffness, and increased left ventricular mass late after aortic coarctation repair: evaluation with magnetic resonance flow mapping. $J$ Thorac Cardiovasc Surg. 2008;135:62-8.

ventricular-arterial elastance mismatch. The peripheral vasculature, meanwhile (and here is where the order of events is uncertain) reacts either to the altered pulse waves distal to the arch or to signals related to initial changes in ventricular elastance and becomes "stiffer" itself, raising systolic blood pressure. The cycle is exacerbated if there is concomitant residual coarctation, persistent hypoplastic arch, or aortopathy associated with bicuspid valve. The fact that impedance mismatch may be an important factor in the pathophysiology is supported by number 5 in the key finding list here, namely that patients with subclavian flap or patch angioplasty have a greater prevalence of subsequent hypertension than those with primary anastomosis in some (but not in all) studies. It is likely that impedance changes at the repair site differ between the two types of repair.

Although the nature of magnitude of ventricular afterload and ventricular-arterial elastance mismatch can and should be elucidated with detailed computational fluid dynamics, much of this proposed sequence of events is biologic, slowly evolving, and thus difficult to measure. Much of the biology is probably in common with that of models proposed for other causes of hypertension, including essential hypertension. We will rely on this broader front of research for a complete understanding of the nature of hypertension after coarctation repair. In the meantime, however, there remains one conceivable, if not practical, surgical solution suggested by the observations. That is, during coarctation repair, reconstruction of the aorta and arch so that they resemble those of the "perfect" proximal vascular anatomy, (impedance matched to the ventricle) might prevent the proposed chain of events leading to hypertension. Seo and coworkers ${ }^{14}$ proposed one such method in 2015, but its effectiveness has not been evaluated. To the extent that 
one believes that arch anatomy is related to risk of subsequent hypertension, use of the direct "pull up" technique (with ascending to descending aortic anastomosis) for coarctation and arch hypoplasia should be used with caution, because it may produce the characteristics of a Gothic arch.

\section{References}

1. Ou P, Celermajer D, Raisky O, Jolivet O, Buyens F, Herment A, et al. Angular (Gothic) aortic arch leads to enhanced systolic wave reflection, central aortic stiffness, and increased left ventricular mass late after aortic coarctation repair: evaluation with magnetic resonance flow mapping. J Thorac Cardiovasc Surg. 2008; $135: 62-8$

2. Canniffe C, Ou P, Walsh K, Bonnet D, Celermajer D. Hypertension after repair of aortic coarctation-a systematic review. Int J Cardiol. 2013;167: 2456-61.

3. Hager A, Kanz S, Kaemmerer H, Schreiber C, Hess J. Coarctation Long-Term Assessment (COALA): significance of arterial hypertension in a cohort of 404 patients up to 27 years after surgical repair of isolated coarctation of the aorta, even in the absence of restenosis and prosthetic material. J Thorac Cardiovasc Surg. 2007; 134:738-45.

4. Luijendijk P, Bouma BJ, Vriend JW, Vliegen HW, Groenink M, Mulder BJ. Usefulness of exercise-induced hypertension as a predictor of chronic hypertension in adults after operative therapy for aortic isthmic coarctation in childhood. Am J Cardiol. 2011;108:435-9.

5. O'Sullivan JJ, Derrick G, Darnell R. Prevalence of hypertension in children after early repair of coarctation of the aorta: a cohort study using casual and 24 hour blood pressure measurement. Heart. 2002;88:163-6.
6. Mery CM, Guzman-Pruneda FA, Trost JG Jr, McLaughlin E, Smith BM, Parekh DR, et al. Contemporary results of aortic coarctation repair through left thoracotomy. Ann Thorac Surg. 2015;100:1039-46.

7. Ou P, Celermajer DS, Mousseaux E, Giron A, Aggoun Y, Szezepanski I, et al Vascular remodeling after "successful" repair of coarctation: impact of aortic arch geometry. J Am Coll Cardiol. 2007;49:883-90.

8. Ou P, Bonnet D, Auriacombe L, Pedroni E, Balleux F, Sidi D, et al. Late systemic hypertension and aortic arch geometry after successful repair of coarctation of the aorta. Eur Heart J. 2004;25:1853-9.

9. Wybraniec MT, Mizia-Stec K, Trojnarska O, Chudek J, Czerwieńska B, Wikarek M, et al. Low plasma renalase concentration in hypertensive patients after surgical repair of coarctation of aorta. J Am Soc Hypertens. 2014;8:464-74.

10. Lee MG, Allen SL, Kawaskaki R, Kotevski A, Koleff J, Kowalski R, et al. High prevalence of hypertension and end-organ damage late after coarctation repair in normal arches. Ann Thorac Surg. 2015;100:647-53.

11. Bruse JL, Khushnood A, McLeod K, Biglino G, Sermesant M, Pennec X, et al How successful is successful? Aortic arch shape following successful aortic coarctation repair correlates with left ventricular function. J Thorac Cardiovasc Surg. 2017;153:418-27.

12. Pedersen TA, Pedersen EB, Munk K, Hjortdal VE, Emmertsen K, Andersen NH, et al. High pulse pressure is not associated with abnormal activation of the reninangiotensin-aldosterone system in repaired aortic coarctation. J Hum Hypertens. 2015;29:268-73

13. Donazzan L, Crepaz R, Stuefer J, Stellin G. Abnormalities of aortic arch shape central aortic flow dynamics, and distensibility predispose to hypertension after successful repair of aortic coarctation. World J Pediatr Congenit Heart Surg. 2014;5:546-53.

14. Seo DM, Park J, Goo HW, Kim YH, Ko JK, Jhang WK. Surgical modification for preventing a gothic arch after aortic arch repair without the use of foreign material. Interact Cardiovasc Thorac Surg. 2015;20:504-9. 